\title{
Exploring the Oral Communication Strategies Used by Turkish EFL Learners: A Mixed Methods Study
}

\author{
Yusuf Demir \\ Dr., Necmettin Erbakan University, Turkey, demir.ysf@hotmail.com \\ Gülçin Mutlu \\ İzmir Democracy University, Turkey, gulcin_berkil@yahoo.com \\ Yavuz Selim Şişman \\ Necmettin Erbakan University, Turkey, yssisman@hotmail.com
}

This study set out with a threefold purpose: to examine (1) the oral communication strategies (CSs) employed by tertiary-level Turkish EFL learners, (2) the use of CSs based on exposure to English through audio-visual tools, university subject domain and gender differences, (3) the correlation between use of CSs and oral proficiency scores. To these ends, a quantitative dominant mixed methods triangulation design was put to use. Yaman and Kavasoğlu's (2013) Turkish adaptation of Oral Communication Strategy Inventory was the main data collection instrument, accompanied by follow-up interviews to corroborate the quantitative findings. Descriptive statistics, t-tests, ANOVA and Pearson productmoment correlations were conducted for statistical analyses while the qualitative data were deductively analysed through a priori theoretical guiding scheme. As a result, the participants were perceived to use oral CSs to some extent, with negotiation for meaning having the top priority. In parallel, as the interview data has shown, the students mentioned using CSs mainly for communication-bound reasons. Moreover, significant differences for CS use appeared only in terms of exposure to English through audio-visual tools in favor of those who reported more frequent exposure. Finally, a positive but weak correlation was calculated between students' overall CS use and oral proficiency scores.

Keywords: oral communication strategies, English as a foreign language (EFL) learners, strategy training, negotiation for meaning, mixed methods research

\section{INTRODUCTION}

With the introduction of communicative competence (Hymes, 1972), communicative approach, and the resulting rapid growth in language is for communication movement since 1970s, communication has been the primary concern of any effort regarding 
foreign language learning and teaching. In parallel, being considered conducive to effective oral communication, the notion of communication strategies (CSs) has gained rapid momentum. As a notion labelled under strategic competence, the ability to employ strategies of language use in order to reach communicative goals (Malasit \& Sarobol, 2013), CSs are a corollary of the mismatch between second language (L2) speakers' linguistic resources and communicative intentions which leads to difficulties or breakdowns in communication (Dörnyei \& Scott, 1997). While CSs have often been viewed as L2 learners' effective tools for communication (Littlemore, 2003), they have also served as a catalyst for the development of research in the related fields of applied linguistics and second language acquisition. Naturally, being a newly-emerging concept at that time, early studies of CSs had a preliminary focus, and therefore centered primarily on defining, identifying and classifying them, while more recent ones have tended to investigate L2 learners' and speakers' use of CSs in different contexts (Koçoğlu, 1997; Mirzaei \& Heidari, 2012), in terms of different factors (Huang, 2010; Bijani \& Sedaghat, 2016; Maldonado, 2016), their relationship with other linguistic components (Khan, 2015; Toomnan \& Intaraprasert, 2015), and moving from such investigations further tended to perform strategy training for using CSs (Maleki, 2007).

Scientific investigation of L2 learners' use of CSs is important, since this provides data regarding their instructional trajectories, specific learning experiences, cultural dispositions, personality traits, and their effects on acquiring CSs. Such a kind of investigation becomes even more worthwhile especially when it is structured around certain variables and characteristics including their proficiency level, cultural contexts, university subject domain, exposure to target language and so on. This is because such research helps to gain an in-depth understanding about the contribution of these factors to the actual use of CSs as a dynamic and modifiable tool, and if any, in what directions and how.

In the specific non-English speaking context of the present study, English as a foreign language (EFL) learners are equipped with the necessary knowledge of language including lexical items, grammatical structures and phonological units, with the communicative purpose of language in the foreground. Despite this multi-pronged encapsulation, it is often the case that these learners fall short in expressing themselves and achieving fluency in English. As a result, more or less, they tend to implement several CSs in order to circumvent these communication problems. In this respect, this study is an endeavor to explore the (extent of) oral CSs used by tertiary-level EFL learners (English preparatory program students) with regard to different variables, and the potential relationship between their use of CSs and oral proficiency. The present study is further motivated by the less amount of research on CSs in comparison to language learning strategies, despite the overriding importance of the former for establishing proficiency for communication. Moreover, this study defines a role for itself in resolving disagreements in the relevant literature concerning the extent to which variables such as proficiency level are related with learners' use of CSs (Nakatani, Makki \& Bradley, 2012). To these ends, the following research questions guided this inquiry:

1. What are the oral CSs used by tertiary-level EFL learners? 
2. Do the extent of CSs used by EFL learners differ in terms of their gender, university subject domain and exposure to English through audio-visual tools?

3. What is the relationship between EFL learners' use of CSs and their oral proficiency scores?

4. What are the perceptions of tertiary-level EFL learners in relation to their preferences for CSs?

\section{Theoretical Framework}

The conceptualization of CSs is mainly framed under psycholinguistic and interactional perspectives, and thus, they are largely defined in the frontiers of these theoretical accounts. The interactional view puts emphasis on the negotiation of meaning between the speaker and the interlocutor in the course of interaction (Rost \& Ross, 1991), and in this sense, views CSs as "a mutual attempt of two interlocutors to agree on a meaning in situations where requisite meaning structures do not seem to be shared." (Tarone, 1980, p. 420). The psycholingustic approach, on the other hand, assigns a problem-solving role to CSs, considering it emergent in a cognitive process within the individual toward comprehension and self-expression (Maleki, 2010). Within this framework, CSs are defined as "potentially conscious plans for solving what to an individual presents as a problem in reaching a particular communicative goal" (Faerch \& Kasper, 1983, p. 36). Both of these approaches are important to consider in researching CSs, since speakers and interlocutors are involved in both cognitive and interactional processes during communication (Uztosun \& Erten, 2014). The importance of this consideration also derives from the fact that applying CSs "may start off as cognitive and result in interaction" (Mali, 2007, p. 41). With such a perspective, the present study adopts a theoretical triangulation of these approaches (Carter et al., 2014) in its bid to explore the array of CSs used by EFL learners in its specific context.

\section{Previous Research on Oral CSs in the Turkish EFL Context}

Oral CS studies in the Turkish context have thus far portrayed in a descriptive manner which strategies are oft-used, in addition to effects of certain variables on the use of CSs and their relationship with certain constructs. To begin with, Koçoğlu (1997) investigated the CSs employed by Turkish EFL learners when communicating with native English speakers, and the effect of the native interlocutors' gender on their use of CSs. It was found that Turkish EFL learners mostly used reduction strategies, paraphrase, cooperative strategies, generalization, word coinage, repetition and repair. In a later study, Kömür and Büyükyavuz (2013) analyzed ELT student teachers' use of CSs for coping with speaking and listening problems by using Nakatani's (2006) Oral Communication Strategies Inventory (OCSI). Based on the evidence from the ELT student teachers who participated in Erasmus Student Exchange Program and interacted with native speakers, it was reported that the use of English in real communication settings makes more meaningful contribution to the development of oral CSs. In their study which investigated oral CSs used by Turkish EFL learners, Yaman, Irgin and Kavasoğlu (2013) found that the most frequently used strategies were negotiation for meaning, compensatory, and getting the gist strategies. In addition, female students employed CSs more than males and high proficiency students. In a similar study, 
Uztosun and Erten (2014) found that the Turkish EFL learners used a limited range of CSs and depended on certain strategies to cope with communication problems. They suggested that this might be caused by students' lack of opportunity to practice using different CSs. The study also revealed that students' proficiency level does not affect the choice of CSs.

\section{METHOD}

\section{Research Design}

The present study adopted a mixed methods triangulation design (quantitative dominant) with a purpose to "obtain different but complementary data on the same topic" (Morse, 1991, p. 122) for a better understanding of the research phenomenon. Given the variants of the triangulation design, it is simply a convergence model as the researchers aimed to "validate, confirm or corroborate quantitative results with qualitative findings" (Creswell \& Clark, 2007, p. 65).

\section{Participants}

For the quantitative phase of the study, the participants were conveniently sampled from B1-level (Threshold level based on CEFR) compulsory English preparatory program students enrolled in a state university in Turkey. When the study data were collected, the students had spent one semester and a month in the preparatory program. Thus, these students were considered to have spent sufficient amount of time in terms of the learning process so as to report their perceived use of oral CSs.

Table 1

Demographic characteristics of participants

\begin{tabular}{|c|c|c|}
\hline Variable & $\mathrm{n}$ & $\%$ \\
\hline \multicolumn{3}{|l|}{ Gender } \\
\hline Female & 113 & 52.6 \\
\hline Male & 102 & 47.4 \\
\hline Total & 215 & 100.00 \\
\hline \multicolumn{3}{|c|}{ Out-of-class exposure to English through audio-visual tools } \\
\hline Always & 19 & 8.8 \\
\hline Frequently & 84 & 39.1 \\
\hline Sometimes & 95 & 44.2 \\
\hline Rarely & 17 & 7.9 \\
\hline Never & 0 & 0 \\
\hline Total & 215 & 100.00 \\
\hline \multicolumn{3}{|c|}{ University subject domain } \\
\hline Science & 92 & 42.8 \\
\hline Social science & 123 & 57.2 \\
\hline Total & 215 & 100.00 \\
\hline
\end{tabular}

For the qualitative phase of the study, maximum variation sampling was performed to see variations with regard to some of the basic demographic characteristics. As the purpose was to "identify important common patterns that cut across variations" (Patton, 2002 , p. 243), the researchers sought for variations through the selection of interviewees 
in relation to similar degrees of representation based on students' gender and university subject domains. In this regard, a total of seven students were interviewed. That is, four students from the aviation management department (two females and two males), two students from the international relations department (one female and one male) and one student from the industrial engineering department (one female) participated in the interviews.

\section{Data Collection Instruments}

\section{Oral Communication Strategies Inventory (OCSI)}

Data from the students' perceptions of the extent of their oral CS use have been collected by means of the adapted version of the Oral Communication Strategy Inventory (Yaman \& Kavasoğlu, 2013), with some minor modifications performed for the present study. For the purposes of this study, only the speaking skills strategies section was employed with the exclusion of two subscales from the original eight-factor instrument. In a previous study, Nakatani (2010) reported an alpha coefficient of .86 on the overall scale. Yaman and Kavasoğlu (2013) performed the Turkish adaptation of the OCSI and retained seven factors with a Cronbach alpha value of .83 on the total inventory. Although Yaman and Kavasoğlu's (2013) adapted version have been used in several studies with satisfying validity and reliability results in the Turkish contexts (see Kömür \& Büyükyavuz, 2013; Arpac1-Somuncu, 2016), some weaknesses related to the Turkish translation and wording, meaningful allocation of the items to the particular scale, and the statistical concerns as to the required number of items for a factor to be reliable (See Tabachnick \& Fidell, 2007) were detected by the researchers, and these were consulted to the experts. Thus, guidance from the expert opinions resulted in a modified OCSI which is composed of 32 items and six subscales elicited on a five-point Likert scale ranging from 1 (never) to 5 (always). The six subfactors adapted for this study (social affective, fluency-oriented, negotiation for meaning, accuracy-oriented, message reduction and alteration, message abandonment) had Cronbach's alpha coefficients of $.68, .64, .69, .57, .61$ and .51 respectively. Moreover, Cronbach's Alpha value of .80 on the total OCSI supported the reliability of the instrument. It was seen, however, for two of the scales, the internal consistency of reliability was lower than the other sub-factors. However, it should be remembered that Cronbach's alpha values are sensitive to the number of items included in the scale and with scales including fewer items than 10, it would be normal to expect low Cronbach's Alpha values (Pallant, 2007). Moreover, Kline (1999) expects lower reliability values when it is the social sciences data. For such situations, Briggs and Cheek (1986) recommended considering the mean inter-item correlation for the items. Thus, the analysis of the inter-item correlations showed an acceptable fit with the presence of an optimal range for the interitem correlations (i.e. between 20 to 40). Therefore, the researchers reported the adapted OCSI in this study as a reliable tool to conduct their further analyses.

\section{Oral Proficiency Scores}

Impromptu speaking tasks were utilized to investigate the learners' oral proficiency scores. These speaking tasks composed one part of the monthly tests administered 
during the spring semester. The scores from these three subsequent tests were aggregated to compose one particular speaking test score. Given the content of the speaking tasks, they were prepared in line with the classroom practice, that is, the contents were similar to daily classroom activities covered in the textbook.

\section{Interviews}

The interviews were conducted through the interview schedule prepared in line with the quantitative concerns of the study. The interviews included two main sections: background questions and questions about content and process. The first section concerning student background data included some questions about the students' experiences with speaking English, and some of their likes and dislikes related to the general English learning process. These questions acted like preparation questions for the following section eliciting the real content and process, that is, the main purpose questions. Then, the following questions "What type of solutions do you seek to overcome the difficulties you experience in communicating with your teachers and peers?" and "Do you think some of the strategies and solutions you use are effective on your achievement in speaking skills?" were asked in the interviewees' mother tongue, i.e. in Turkish.

\section{Data Analysis}

For the quantitative phase of the study, before the main analyses, the obtained data were screened and cleaned through the confirmation of missing values not exceeding 5\% of the whole data. Descriptive statistics, t-tests, ANOVA and Pearson product-moment correlations were conducted for statistical analyses. In advance of all the quantitative analyses, required statistical assumptions were checked against any violations. Before each of the main analyses, the assumption of normality, that is, whether the data show normal distribution or not was checked by means of Skewness and Kurtosis values, Kolmogorov-Smirnov and Shapiro-Wilks Tests as well as the examination of histograms and normal Q-Q plots for the study variables included in each research question. The results from these analyses revealed that the assumptions of normality of sampling distributions were met throughout.

With regard to the analysis of the qualitative data, the interview data were deductively analysed. In such an approach, "the researcher looks for predetermined, existing subjects by testing hypotheses or principles..." (Bengtsson, 2016, p. 10) and "has to create a coding list before starting the analyzing process" (p. 12), usually derived from the relevant literature so as to code the data. With a priori theoretical guiding scheme to examine the data, it is way easier to obtain high reliability (Catanzaro, 1988). For the coding of the qualitative data, in this study, categories were borrowed from the strategy subdimensions available in the instrument (OCSI) used for the quantitative phase of this study, which are also present in Nakatani's original inventory. Following the transcription of the data, the students' verbal reflections toward their strategy moves (e.g. using fillers) were embedded into the related subcategory (social affective subcategory in this case) through the collaborative coding of the three researchers. Such an approach to qualitative data analysis, also called investigator triangulation which 
requires the gathering of multiple researchers in investigating the same problem, helped promote the credibility and conformability of the analysis (Anney, 2014), and thus provided trustworthiness for the analysis (Guba \& Lincoln, 1981).

\section{FINDINGS}

\section{Oral CSs Used by Tertiary-Level EFL Learners}

Table 2 displays the mean frequencies for all participants on the whole OCSI and seven subcategories. When the average score of the means of all the participants on the whole OCSI on a five-point Likert scale is examined, it is seen that the participants' use of CSs falls within the range of medium-to-high frequency $(\overline{\boldsymbol{x}}=3.50, S D=.38)$. When the average scores are examined in terms of subcategories, negotiation for meaning demonstrates the highest $(\bar{x}=3.76, S D=.48)$ falling within the range of medium-tohigh frequency whereas message abandonment subcategory has the lowest means $(\overline{\boldsymbol{x}}=$ $2.62, S D=.81$ ), being within the range of low-to-medium frequency. The remaining four subcategories fall within medium-to-high frequency in a descending order as fluencyoriented $(\overline{\boldsymbol{x}}=3.62, S D=.62)$, message reduction and alteration $(\overline{\boldsymbol{x}}=3.62, S D=.61)$, social affective $(\overline{\boldsymbol{x}}=3.44, S D=.64)$, and accuracy-oriented $(\overline{\boldsymbol{x}}=3.25, S D=.78)$.

Table 2

Participants' oral CS use based on the total scale and subcategories

\begin{tabular}{lccc}
\hline OCSI Subcategory & $\mathrm{N}$ & $\overline{\boldsymbol{x}}$ & $\mathrm{SD}$ \\
\hline social affective (SA) & 215 & 3.44 & .64 \\
\hline negotiation for meaning (NM) & 215 & 3.76 & .48 \\
\hline message abandonment (MA) & 215 & 2.62 & .81 \\
\hline message reduction and alteration (MR) & 215 & 3.62 & .61 \\
\hline accuracy-oriented (AO) & 215 & 3.25 & .78 \\
\hline fluency-oriented (FO) & 215 & 3.62 & .62 \\
\hline total OCSI (TO) & 215 & 3.50 & .38 \\
\hline *1.00-2.00(Low), 2.01-3.00(Low-to-Medium), 3.01-4.00(Medium-to-High), 4.01-5.00(High)
\end{tabular}

\section{Differences in the Use of OCSs in terms of Student-related Variables}

\section{Differences in the use of OCSs in terms of Gender}

Given the mean scores of males and females in terms of the frequency of oral CS use, there is a little difference between the two groups, with females having a higher oral CS frequency $(\overline{\boldsymbol{x}}=3.52, S D=.39)$ than the males $(\overline{\boldsymbol{x}}=3.47, S D=.37)$. In order to test if this difference was significant, an independent samples t-test was conducted. As is evident in Table 3, the results showed that there was no statistically significant difference in the frequency of oral CS use by males and males.

Table 3

T test for Gender in relation to Oral CS Use

\begin{tabular}{llllll}
\hline Groups & $\overline{\boldsymbol{x}}$ & $\mathrm{SD}$ & $\mathrm{t}$ & $\mathrm{df}$ & $\mathrm{p}$ \\
\hline female $(n=113)$ & 3.52 & .39 & .883 & 213 & .378 \\
\hline Male $(n=102)$ & 3.47 & 0,37 & & & \\
\hline$p>.05$ & & & & &
\end{tabular}




\section{Differences in the use of CSs in terms of University Subject Domain}

Given the means for the students from the social sciences-related departments $(\overline{\boldsymbol{x}}=$ $3.53, S D=.40)$ and those from the science related departments $(\overline{\boldsymbol{x}}=3.45, S D=.35)$, there is a slight difference between the two groups, with the former having a little higher mean for CS use than the latter group. However, as shown in Table 4, no statistical difference was observed between the means of the two groups, which means that there is no statistically significant difference in the oral CS use in terms of the students' subject domains $(t(213)=1.47, p>.05)$.

Table 4

$\mathrm{T}$ test for University Subject Domain in relation to Oral CS Use

\begin{tabular}{llllll}
\hline Groups & $\overline{\boldsymbol{x}}$ & $\mathrm{SD}$ & $\mathrm{t}$ & $\mathrm{df}$ & $\mathrm{p}$ \\
\hline social sciences $(\mathrm{n}=123)$ & 3.53 & .40 & 1.468 & 213 & .144 \\
\hline science $(\mathrm{n}=92)$ & 3.45 & .35 & & & \\
\hline$p>.05$ & & & &
\end{tabular}

Differences in the Use of OCSs in terms of Out-of-class Exposure to English through Audio-visual Tools

A one-way between-groups analysis of variance was conducted to examine the effect of out-of-class exposure to English through audio-visual tools on the frequency of oral CS use. The independent variable, out-of-class exposure to English through audio-visual tools included five levels: never, rarely, sometimes, usually and always. The dependent variable was the participants' frequency of oral CS use. The ANOVA was significant, $F$ $(3,211)=4.88, p=.003$ (Table 5). The strength of the relationship between the frequency of oral CS use and out-of-class exposure to English through audio-visual tools, as assessed by $\eta^{2}$ (Eta squared), was medium, which means that only $6 \%$ of the variance in the participants' oral CS use is explained by the participants' out-of-class exposure to English through audio-visual tools. Post-hoc comparisons using the Tukey HSD test indicated that the mean score for those students reporting their exposure as always ( $\overline{\boldsymbol{x}}=3.73, S D=.36)$ was significantly different from those with sometimes frequency reportings $(\bar{x}=3.44, S D=.36)$, and from those with rarely frequency reportings $(\dot{\boldsymbol{x}}=3.35, S D=.44)$. Those with always frequency reportings $(\overline{\boldsymbol{x}}=3.73, S D$ $=.36$ ) and often frequency reportings $(\overline{\boldsymbol{x}}=3.54, S D=.36)$, and similarly, those with rarely and sometimes or often frequency reportings were not statistically different from one another in terms of their oral CS use although there appears to be a slight difference based on their mean values.

Table 5

ANOVA Summary Table

\begin{tabular}{llllll}
\hline Source & SS & df & MS & F & Direction of Differences \\
\hline Exposure Group & 2017.56 & 3 & 672.52 & $4.88^{*}$ & $\mathrm{D}<\mathrm{A}^{*}, \mathrm{C}<\mathrm{A}^{*}$ \\
\hline Error & 29152.98 & 211 & 138.17 & & \\
\hline Total & 31170.54 & 214 & & & \\
\hline
\end{tabular}

* $p<.01 ; \mathrm{A}=$ always reportings for out-of-class exposure; $\mathrm{C}=$ sometimes reportings for out-of-class exposure; $\mathrm{D}=$ rarely reportings for out-of-class exposure. 


\section{Relationship between EFL Learners' Use of Oral CSs and Their Oral Proficiency Scores}

The potential relationship between students' oral proficiency scores and frequency of oral CS use, computed as a total score on the whole OCSI and also with regard to the six subcategories, was investigated using Pearson product-moment correlation coefficient. The results of the correlational analyses presented in Table 6 show that five out of seven correlations were statistically significant and were greater than or equal to .13. That is, there was a relatively weak positive correlation between the students' oral communication proficiency scores and the total frequency score they got from the whole OCSI $(r=.14, p<.05)$, and the subcategory mean frequency they got from the social affective strategies $(r=.15, p<.05)$. Similarly, the correlation between oral CS use and the remaining three strategy subcategories, message abandonment, accuracy-oriented and fluency-oriented sub-dimensions were statistically significant, but suggesting again a small relationship between subcategory-based oral CS use and students' oral proficiency levels. For the positively associated strategy subcategories, high levels of oral CS use were related to higher levels of oral proficiency gains. Given the presence of any significantly and negatively associated strategy subcategories, the direction of the relationship was found to be negative only for the message abandonment subcategory and there was still a small correlation between this sub-factor and oral proficiency scores. The strategy items with no significant correlations with the students' oral proficiency scores were those from the negotiation for meaning and message reduction and alteration subcategories.

Table 6

Pearson product-moment correlations between oral proficiency scores and oral CS use (on OCSI subcategories and the whole OCSI)

\begin{tabular}{lll}
\hline Scales compared to the oral proficiency scores & $\mathrm{r}$ & $p$ \\
\hline Social affective (SA) & .15 & $.029^{*}$ \\
\hline Negotiation for meaning (NM) & .13 & .074 \\
\hline Message abandonment (MA) & -.26 & $.000^{*}$ \\
\hline Message reduction and alteration (MR) & -.14 & .052 \\
\hline Accuracy-oriented (AO) & .25 & $.000^{*}$ \\
\hline Fluency-oriented (FO) & .23 & $.001^{*}$ \\
\hline Total OCSI (TO) & .14 & $.045^{*}$ \\
\hline
\end{tabular}
$* p<.05$

\section{Follow-up Findings of the Students' Use of CSs}

Serving as a follow-up and complementary, this part reports the interviewees' stated strategy moves under the related categories in an effort to corroborate and build on the quantitative findings of the first research question (i.e. their use of CSs as elicited through the OCSI instrument). As can be seen in Table 7, the participants stated using several strategies which include compensatory replacement, simplification, diversification, the use of body language, gestures, mimics, eye contact, fillers, examples, equivalents/similar structures and vocabulary, simultaneous visuals, tracking interlocutors' facial expressions, repeating utterances/extra explanation, smiling, playing 
safe in terms of vocabulary use, receiving/providing peer assistance, taking the time to devise the speech. Given the related categories, these strategies were associated with and represented the following strategy categories: Negotiation for Meaning While Speaking, Message Reduction and Alteration, Social Affective, Fluency-Oriented, Message Abandonment and Attempt to Think in English. Accuracy-oriented strategy category was the only one which was not touched upon and thus not represented in the interviewees' accounts.

Moreover, as a byproduct of the main research concerns, analysis of the data further revealed the functions and rationales behind the participants' use of particular strategies. When these functions and rationales are amalgamated, the participants were perceived to use strategies, to a large extent, to realize trouble-free communication purposes such as expressing themselves better, conveying the message more clearly, consolidating and facilitating interlocutors' understanding of the message. Apart from the communicationoriented purposes, the participants also reported a number of reasons for the strategies they employed which included reducing stress, gaining time, attracting listeners' focus and attention, thinking faster, enhancing linguistic productivity and positive energy, relieving the monotony, providing more retention, retrieving words and receiving dis/approval to further the speech.

Table 7

Analyzed version of the interviewees' reflections

\begin{tabular}{|c|c|c|c|}
\hline Strategy & Category & Rationale & Example/Quotation \\
\hline Body language & $\begin{array}{l}\text { Negotiation for } \\
\text { Meaning While } \\
\text { Speaking }\end{array}$ & $\begin{array}{l}\text { On the part of the strategy user } \\
\text { To express oneself more easily } \\
\text { To reduce stress }\end{array}$ & $\begin{array}{l}\text { "I can express myself better through } \\
\text { body language." } \\
\text { "I feel nervous and cannot speak if I } \\
\text { don't use body language". }\end{array}$ \\
\hline $\begin{array}{l}\text { Compensatory } \\
\text { replacement }\end{array}$ & $\begin{array}{l}\text { Message } \\
\text { Reduction and } \\
\text { Alteration }\end{array}$ & $\begin{array}{l}\text { On the part of the strategy user } \\
\text { To express oneself in different } \\
\text { ways }\end{array}$ & $\begin{array}{l}\text { 1. "How much sugar do you need?" } \\
\text { when the student has difficulty } \\
\text { retrieving the quantifiers such as well } \\
\text { sugared, with a middling amount or } \\
\text { little sugared } \\
\text { 2. If the student has difficulty giving } \\
\text { directions for location B, defining it } \\
\text { between the locations A and C. }\end{array}$ \\
\hline $\begin{array}{l}\text { Using visuals } \\
\text { simultaneously }\end{array}$ & $\begin{array}{l}\text { Negotiation for } \\
\text { Meaning While } \\
\text { Speaking }\end{array}$ & $\begin{array}{l}\text { On the part of the strategy user } \\
\text { To express oneself better } \\
\text { To convey the message more } \\
\text { clearly }\end{array}$ & $\begin{array}{l}\text { Making use of a direction sign to give a } \\
\text { direction }\end{array}$ \\
\hline $\begin{array}{l}\text { Tracking } \\
\text { interlocutors' } \\
\text { facial expressions }\end{array}$ & $\begin{array}{l}\text { Negotiation for } \\
\text { Meaning While } \\
\text { Speaking }\end{array}$ & $\begin{array}{l}\text { On the part of the interlocutor } \\
\text { To check for interlocutors' } \\
\text { understanding } \\
\text { On the part of the strategy user } \\
\text { To receive dis/approval to } \\
\text { further the speech }\end{array}$ & $\begin{array}{l}\text { "I check the listener's understanding } \\
\text { by looking at his/her facial } \\
\text { expressions. He/she provides a hint } \\
\text { somehow". } \\
\text { "I am aware that the listener nods } \\
\text { her/hand as an approval. This makes } \\
\text { me further the topic". }\end{array}$ \\
\hline $\begin{array}{l}\text { Repeating } \\
\text { utterances/extra } \\
\text { explanation }\end{array}$ & $\begin{array}{l}\text { Negotiation for } \\
\text { Meaning While } \\
\text { Speaking }\end{array}$ & $\begin{array}{l}\text { On the part of the interlocutor } \\
\text { To consolidate interlocutors' } \\
\text { understanding }\end{array}$ & $\begin{array}{l}\text { "I am repeating the words so as to } \\
\text { make my message more clear". }\end{array}$ \\
\hline Using fillers & Social Affective & $\begin{array}{l}\text { On the part of the strategy user } \\
\text { To gain time }\end{array}$ & You see, well, errr \\
\hline
\end{tabular}




\begin{tabular}{|c|c|c|c|}
\hline Using examples & $\begin{array}{l}\text { Negotiation for } \\
\text { Meaning While } \\
\text { Speaking }\end{array}$ & $\begin{array}{l}\text { On the part of the strategy user } \\
\text { To think faster } \\
\text { To retrieve more words } \\
\text { On the part of the interlocutor } \\
\text { To attract listeners' focus and } \\
\text { attention } \\
\text { To facilitate understanding }\end{array}$ & For example, for instance... \\
\hline $\begin{array}{l}\text { Using } \\
\text { equivalents/ } \\
\text { similar structures } \\
\text { and vocabulary }\end{array}$ & $\begin{array}{l}\text { Message } \\
\text { Reduction and } \\
\text { Alteration }\end{array}$ & $\begin{array}{l}\text { On the part of the strategy user } \\
\text { To pursue communication }\end{array}$ & $\begin{array}{l}\text { The use of present perfect instead of } \\
\text { simple past, } \\
\text { Can instead of could, metro instead of } \\
\text { underground }\end{array}$ \\
\hline Simplification & $\begin{array}{l}\text { Message } \\
\text { Reduction and } \\
\text { Alteration }\end{array}$ & $\begin{array}{l}\text { On the part of the strategy user } \\
\text { To express oneself better } \\
\text { On the part of the interlocutor } \\
\text { To facilitate understanding }\end{array}$ & "become good" instead of "recover" \\
\hline Diversification & $\begin{array}{l}\text { Fluency- } \\
\text { Oriented }\end{array}$ & $\begin{array}{l}\text { On the part of the strategy user } \\
\text { To relieve the monotony }\end{array}$ & $\begin{array}{l}\text { Using different discourse markers that } \\
\text { have the same meaning }\end{array}$ \\
\hline $\begin{array}{l}\text { Gestures, mimics, } \\
\text { eye contact }\end{array}$ & $\begin{array}{l}\text { Negotiation for } \\
\text { Meaning While } \\
\text { Speaking }\end{array}$ & $\begin{array}{l}\text { On the part of the strategy user } \\
\text { To think faster } \\
\text { To enhance linguistic } \\
\text { productivity }\end{array}$ & $\begin{array}{l}\text { "When I use gestures, I can think faster } \\
\text { and recall more words". }\end{array}$ \\
\hline Smiling & Social Affective & $\begin{array}{l}\text { On the part of the strategy user } \\
\text { To create positive energy }\end{array}$ & $\begin{array}{l}\text { "In my opinion, it is important to smile } \\
\text { while you are speaking. This helps me } \\
\text { transmit positive energy, and in turn, } \\
\text { receive positive energy". }\end{array}$ \\
\hline $\begin{array}{l}\text { Playing safe in } \\
\text { terms of } \\
\text { vocabulary use }\end{array}$ & $\begin{array}{l}\text { Message } \\
\text { Reduction and } \\
\text { Alteration } \\
\text { Strategies }\end{array}$ & $\begin{array}{l}\text { On the part of the strategy user } \\
\text { To convey the message more } \\
\text { clearly }\end{array}$ & $\begin{array}{l}\text { "I prefer to use the vocabulary that I } \\
\text { am sure I know of". }\end{array}$ \\
\hline $\begin{array}{l}\text { Receiving/providi } \\
\text { ng peer assistance }\end{array}$ & $\begin{array}{l}\text { Message } \\
\text { Abandonment }\end{array}$ & $\begin{array}{l}\text { On the part of the strategy user } \\
\text { To convey the meaning } \\
\text { On the part of the interlocutor } \\
\text { To ensure understanding } \\
\text { To provide more retention }\end{array}$ & $\begin{array}{l}\text { "In my current class, my peers are } \\
\text { inclined to correct each other. They } \\
\text { understand me better than the teacher, } \\
\text { and therefore, they directly convey my } \\
\text { point to the teacher in English". } \\
\text { "Being corrected by peers helps me } \\
\text { retain words more easily". }\end{array}$ \\
\hline $\begin{array}{l}\text { Taking the time } \\
\text { to devise the } \\
\text { speech }\end{array}$ & $\begin{array}{l}\text { Attempt to } \\
\text { Think in } \\
\text { English }\end{array}$ & $\begin{array}{l}\text { On the part of the strategy user } \\
\text { To speak more effectively }\end{array}$ & $\begin{array}{l}\text { "It seems to me that the speech } \\
\text { becomes more effective when I think } \\
\text { over and make the utterance in one } \\
\text { go". }\end{array}$ \\
\hline
\end{tabular}

\section{DISCUSSION}

The first major finding of the present study is that the tertiary EFL learner participants were perceived to use oral CS at a level that is higher than the average score $(\bar{x}=3.50$ out of 5.00, at medium-to-high level) though this demonstrates a level that is distant to the maximum potential. Given the average scores of the subcategories of the CSs, it was revealed that negotiation for meaning strategies were the most widely used strategies by the participants ( $\overline{\boldsymbol{x}}=3.76$ out of 5.00 , at medium-to-high level). The students' frequent use of negotiation for meaning strategies are favored by Long's (1996) Interaction hypothesis in the sense that the negotiated interaction between the learner and the teacher, which results from the need to negotiate the meaning, facilitates L2 
development. Negotiation for meaning, Long asserts, sparks interactional adjustments by more competent interlocutors (i.e. teachers), which helps to make connections among "input, internal learner capacities, particularly selective attention, and output in productive ways" (p. 451-452), and therefore facilitates L2 learning. Negotiation for meaning, as a move oriented toward resolving communication breakdowns and working toward mutual comprehension (Pica, Holliday, Lewis \& Morgenthaler, 1989), by leading to interactional modifications, makes it possible for L2 learners to get the necessary input from their interlocutors. In these respects, while the students' frequent use of negotiation for meaning strategies implies the communicative orientation of their classes, the interviewees' verbal accounts that reflected their rationales for the use of CSs corroborate this assumption. As the interview data revealed, the students reported using CSs, to a significant extent, in order to establish trouble-free communication purposes such as expressing themselves clearly, conveying the meaning smoothly, and facilitating interlocutors' understanding of the message.

When the relationship between students' gender and their use of oral CSs were examined, it was seen that there was no statistically significant difference in the mean scores of males and females in terms of the frequency of oral CS use. These results are consistent with the previous research on oral CSs. Working again with the university students in a Taiwanese context and utilizing the Nakatani's (2006) OCSI, Huang (2010) found no effects of gender on the use of oral CSs. There was also some contrasting evidence on this issue. Li (2010), for instance, found a significant difference between males and females in the use of oral CSs with females reporting more frequency of oral CS use.

Given the association between out-of-class exposure to English through audio-visual tools and the frequency of oral CS use, it was revealed that the participants' strategy use significantly varied by their out-of-class exposure to English and this variation occurred between those students with always and those with sometimes and rarely out-of-class exposure reportings to English. In this regard, with the presence of no never reportings in relation to the level of exposure, it is seen that a significant difference occurred only when the participants' level of frequency was observed at the poles. That is, there is a bigger frequency range when always reportings were compared to rarely and sometimes frequency levels than the other probable comparisons between the other particular frequency levels elicited in the instrument. In the same vein, Piranian (1979) reported that those language learners with more exposure to the target language were more successful in the use of oral CSs.

When the relationship between the students' oral CS use and their oral proficiency scores was investigated, the results indicated positive but weak correlations between strategy use and oral proficiency in terms of overall strategy use on the whole OCSI and also on four OCSI sub-scales. In this sense, it could be drawn from these results that the more frequent one employs oral CSs, the better oral proficiency scores he or she has in English, and vice versa. Huang and Naerssen's study (1987) showed supporting evidence to the results of this study. These researchers investigated the differences in learners' oral communication abilities by their frequency of oral CSs. In this regard, they 
categorized students into three different groups with regard to their frequency of strategy use. Comparing low use students to middle and high frequency use groups, they found that middle and high frequency students were significantly different from their low use counterparts in terms of their oral proficiency abilities with the two higher frequency group students gaining better oral proficiency scores. Thus, supporting the results from Huang and Naerssen's study (1987), the findings from this current research also implied a parallelism between the frequency of strategy use and one's oral performance.

\section{IMPLICATIONS}

This study showed that the students with more exposure to English outside the school through audio-visual tools demonstrated higher uses of oral CSs than those with less exposure. In addition, their verbal accounts revealed their use of visual tools as a useful strategy to facilitate the conveying of meaning. Therefore, EFL learners should be prompted to draw from the benefits of recent technologies and audio-visual tools, through a number of exemplars and tools which are not limited to ICT, mobile applications, online practice opportunities, audiobooks and so on. Also, the ELT classroom environment needs to be enriched with visual tools such as realia, images etc. to allow for more meaningful negotiated interaction. What is more, while the L2 teacher is potentially the best role model in hand, strategy training for the use of oral CSs can also be effectively conducted with the inclusion of native and non-native interlocutors with different cultural and educational backgrounds. No doubt, this can help students enrich their strategy repertoires.

This study documented the EFL learners' stated use of oral CSs in the present context. Further studies could center upon the analysis of authentic speech to provide further insights into the use of these strategies by EFL learners. Such a study could also pave the way for the comparison of students' stated and actual use of oral CSs. Another worthwhile investigation would be to discover the parallelism between EFL learners' use of oral CSs in their native language and in the target language.

\section{REFERENCES}

Anney, V. N. (2014). Ensuring the quality of the findings of qualitative research: Looking at trustworthiness criteria. Journal of Emerging Trends in Educational Research and Policy Studies, 5(2), 272-281.

Arpac1-Somuncu, D. (2016). Turkish EFL learners' use of communication strategies and its predictors. ELT Research Journal, 5(3), 178-192.

Bengtsson, M. (2016). How to plan and perform a qualitative study using content analysis. NursingPlus Open, 2, 8-14.

Bijani, H., \& Sedaghat, A. (2016). The application of communication strategies by students with different levels of communication apprehension in EFL context. Theory and Practice in Language Studies, 6(2), 366.

Briggs, S. R., \& Cheek, J. M. (1986). The role of factor analysis in the development and evaluation of personality scales. Journal of personality, 54(1), 106-148. 
Carter, N., Bryant-Lukosius, D., DiCenso, A., Blythe, J., \& Neville, A. J. (2014). The use of triangulation in qualitative research. In Oncology nursing forum (Vol. 41, No. 5).

Catanzaro, M. (1988). Using qualitative analytical techniques. In Nursing Research; Theory and Practice (Woods P. \& Catanzaro M., eds), C.V. Mosby Company, New York, pp. 437-456.

Creswell, J. W., \& Clark, V. L. P. (2007). Designing and conducting mixed methods research. Thousand Oaks, CA: Sage Publications

Dörnyei, Z., \& Scott, M. L. (1997). Communication strategies in a second language: Definitions and taxonomies. Language learning, 47(1), 173-210.

Faerch, C., \& Kasper, G. (1983). Strategies in interlanguage communication. London:

Longman.

Guba, E. G., \& Lincoln, Y. S. (1981). Effective evaluation: Improving the usefulness of evaluation results through responsive and naturalistic approaches. Jossey-Bass.

Huang, X. H., \& Naerssen, M. V. (1987). Learning strategies for oral communication. Applied linguistics, 8(3), 287-307.

Huang, C. P. (2010). Exploring factors affecting the use of oral communication strategies. LongHua Technology University Journal, 30, 85-104.

Hymes, D. (1972). On communicative competence. Sociolinguistics, 269293, 269-293.

Khan, S. M. (2015). Influence of speech anxiety on oral communication skills among ESL/EFL learners. Advances in Language and Literary Studies, 6(6), 49-53.

Kline, P. (1999). The handbook of psychological testing (2nd ed.). London: Routledge

Koçoğlu, Z. (1997). The role of gender in communication strategy use. Paper presented at the 31st Annual Meeting of the Teachers of English to Speakers of Other Languages, Orlando, FL, March 11-15, 1997.

Kömür, Ş., \& Büyükyavuz, O. (2013). A comparative evaluation of preservice English teachers' coping strategies in oral communication. Képzés És Gyakorlat, 11, 108-124.

Li, R. L. (2010). The relationship between speaking anxiety and speaking strategies among university students in Taiwan. Unpublished Master thesis, National Ping Tong University of Education, Ping Tong, Taiwan.

Littlemore, J. (2003). The communicative effectiveness of different types of communication strategy. System, 31(3), 331-347.

Long, M. (1996). The role of the linguistic environment in second language acquisition. In W. Ritchie \& T. Bhatia (Eds.), Handbook of second language acquisition. San Diego: Academic Press. 
Malasit, Y., \& Sarobol, N. (2013). Communication strategies used by Thai EFL learners. In Proceedings of International Conference on Foreign Language Learning and Teaching (pp. 802-815).

Maldonado, M. R. (2016). Communication strategies used by different level L2 English learners in oral interaction. Revista signos, 49(90), 71-93.

Maleki, A. (2007). Teachability of communication strategies: An Iranian experience. System, 35(4), 583-594.

Maleki, A. (2010). Techniques to teach communication strategies. Journal of Language Teaching \& Research, 1(5), 640-646.

Mali, Z. O. (2007). Exploring communication strategy use by learners of Isizulu in Synchronous computer-mediated communication $(S-C M C)$. Unpublished Doctoral dissertation. The University of Iowa.

Mirzaei, A., \& Heidari, N. (2012). Exploring the use of oral communication strategies by (Non) fluent L2 speakers. The Journal of AsiaTEFL, 9(3), 131-156.

Morse, J. M. (1991). Approaches to qualitative-quantitative methodological triangulation. Nursing research, 40(2), 120-123.

Nakatani, Y. (2006). Developing an oral communication strategy inventory. The Modern Language Journal, 90(2), 151-168.

Nakatani, Y. (2010). Identifying strategies that facilitate EFL learners' oral communication: A classroom study using multiple data collection procedures. The Modern Language Journal, 94(1), 116-136.

Nakatani, Y., Makki, M., \& Bradley, J. (2012). 'Free' to choose: Communication strategy use in EFL classrooms in Iran. Iranian Journal of Applied Linguistics, 15(2), 61-83.

Pallant, J. (2007). SPSS survival manual: A step-by-step guide to data analysis using SPSS version 15. Nova Iorque: McGraw Hill.

Patton, M. Q. (2002). Qualitative research and evaluation methods. California EU: Sage Publications Inc.

Pica, T., Holliday, L., Lewis, N., \& Morgenthaler, L. (1989). Comprehensible output as an outcome of linguistic demands on the learner. Studies in Second Language Acquisition, 11, 63-90.

Piranian, D. 1979. Communication strategies of foreign language learners: a pilot study. Unpublished manuscript, Slavic Linguistics, University of Washington.

Rost, M., \& Ross, S. (1991). Learner use of strategies in interaction: Typology and teachability. Language learning, 41(2), 235-268.

Tabachnick, B. G., \& Fidell, L. S. (2007). Using multivariate statistics. Boston: Allyn and Bacon 
Tarone, E. (1980). Communication strategies, foreigner talk and repair in interlanguage.

Language Learning, 30, 417-431.

Toomnan, P., \& Intaraprasert, C. (2015). The impacts of attitude towards speaking English on the use of communication strategies by English majors in Thailand. Theory and Practice in Language Studies, 5(6), 1151-1158.

Uztosun, M. S., \& Erten, İ. H. (2014). The impact of English proficiency on the use of communication strategies: An interaction-based study in Turkish EFL context. Journal of Language and Linguistic Studies, 10(2), 169-182.

Yaman, Ş., Irgin, P., \& Kavasoğlu, M. (2013). Communication strategies: Implications for EFL university students. Journal of Educational Sciences Research, 3(2), 255-268.

Yaman, S., \& Kavasoğlu, M. (2013). The adaptation study of oral communication strategy inventory into Turkish. Journal of Human Sciences, 10(2), 400-419. 